\title{
Identification of Sunflower (Helianthus annuus) Accessions Resistant to Diaporthe helianthi and Diaporthe gulyae
}

Febina M. Mathew ${ }^{\dagger}$ and Taylor R. Olson, Department of Agronomy, Horticulture and Plant Science, South Dakota State University, Brookings, 57007; Laura F. Marek, Department of Agronomy, lowa State University, Ames, 50011; Thomas J. Gulya, United States Department of Agriculture-Agricultural Research Service (USDA-ARS), Northern Crop Science Laboratory, Fargo, ND 58108 (retired); and Samuel G. Markell, Department of Plant Pathology, North Dakota State University, Fargo, 58102

Accepted for publication 2 March 2018.

\section{Abstract}

Phomopsis stem canker is an important disease on sunflower (Helianthus annuus) in Minnesota, North Dakota, and South Dakota. To date, Diaporthe helianthi and D. gulyae have been reported as the common and primary causal agents in this region. The objectives of this study were to compare aggressiveness of the two species and evaluate the USDA cultivated sunflower germplasm collection for resistance to the two pathogens. Five $D$. helianthi isolates and five $D$. gulyae isolates were compared for their aggressiveness on the USDA susceptible confection inbred 'HA 288' using the stem- wound inoculation method. The results of this study demonstrated that $D$. helianthi and $D$. gulyae isolates did not vary significantly $(P>0.05)$ in their aggressiveness. Using a representative isolate of $D$. helianthi and D. gulyae, 49 accessions were screened for Phomopsis stem canker using the stem-wound method in the greenhouse. Among the 49 accessions, 13 and 4 accessions were less susceptible to $D$. helianthi and D. gulyae, respectively, compared with HA 288. Only one accession (PI 552939) was observed to be significantly less susceptible to both $D$. helianthi and D. gulyae when compared with HA 288.
Phomopsis stem canker is one of the most economically important diseases of sunflower (Helianthus annuus L.) in the world (Harveson et al. 2016; Masirevic and Gulya 1992). Yield losses in excess of $40 \%$ have been reported in Europe, South America, and North America, and the disease also occurs in Asia and Australia (Harveson et al. 2016). Recently, the disease reemerged in the United States (Mathew et al. 2015). The prevalence of Phomopsis stem canker in some areas of the Northern Great Plains (Minnesota, North Dakota, and South Dakota), where $>75 \%$ of the nation's sunflower is planted, has exceeded $50 \%$ in some years (Gulya and Kandel 2016). Phomopsis stem canker is a major economic concern for sunflower growers in the United States, and improvement of management strategies is a top research priority for the U.S. National Sunflower Association (Gulya and Kandel 2016).

Multiple species of Diaporthe are documented causing Phomopsis stem canker on sunflower, including D. helianthi MuntañolaCvetkovic, Mihaljcevic and Petrov (Masirevic and Gulya 1992; Muntañola-Cvetković et al. 1985), D. gulyae Shivas, Thompson and Young (Thompson et al. 2011), D. kochmanii Shivas, Thompson and Young (Thompson et al. 2011), D. kongii Shivas, Thompson and Young (Thompson et al. 2011), D. stewartii Harrison (Mathew et al. 2012; Olson et al. 2017), D. phaseolorum (Cooke and Ellis) Saccardo (Vrandečić et al. 2009), and D. novem Santos, Vrandečić and Phillips (Thompson et al. 2015). In 2015, Udayanga et al. (2015) reclassified $D$. kochmanii and D. phaseolorum as part of a D. sojae species complex. Three species of Diaporthe have been reported causing

\section{Corresponding author: Febina M. Mathew; E-mail: febina.mathew@sdstate.edu}

Funding: This work was funded by the National Sunflower Association (Mandan, ND), the South Dakota Oilseeds Council (Pierre, SD), and the South Dakota Agricultural Experimental Station (Hatch Project H527-14).

(C) 2018 The American Phytopathological Society
Phomopsis stem canker of sunflower in the United States: D. helianthi (Herr et al. 1983; Mathew et al. 2015), D. gulyae (Mathew et al. 2015), and D. stewartii (Mathew et al. 2012; Olson et al. 2017). Among those three species of Diaporthe, D. helianthi and D. gulyae are prevalent in the Northern Great Plains (Minnesota, North Dakota, and South Dakota) and pathogenic on sunflower (Mathew 2014; Mathew et al. 2015).

Genetic resistance may provide a useful management tool for Phomopsis stem canker, and sources of resistance have been identified from wild and cultivated Helianthus accessions. For example, Gulya et al. (2009) screened a total of 1,106 accessions of the USDA cultivated sunflower collection in the former Yugoslavia (499 accessions) and the United States (northwestern Minnesota; 607 accessions), and $2 \%$ of the entries were observed to have $<10 \%$ disease incidence. In addition, a number of wild Helianthus species (e.g., H. maximiliani, H. hirsutus, $H$. pauciflorus, $H$. mollis, $H$. resinosus, and $H$. tuberosus) were reported to have resistance to $D$. helianthi (Cuk 1982; Dozet 1990; Škorić 1984). More recently, Talukder et al. (2014) identified possible sources of resistance to D. helianthi in parental lines from Russia and Europe. However, there are currently no commercial sunflower hybrids available in the United States with complete resistance to D. helianthi and D. gulyae.

The majority of breeding efforts for Phomopsis stem canker resistance have been under natural-infection conditions in the field, in which ascospores infect leaf tissue and the disease progresses through the petiole into the stem. Field screening can result in a wide distribution of resistance or susceptible reactions (Langar et al. 2000) and discrimination among genotypes (Degener et al. 1999). However, the selection for resistant hybrids in the field takes an entire growing season to complete, results are heavily dependent on environmental conditions, and the process is labor and cost intensive. Additionally, virulence differences within and among Diaporthe species are known to occur, which can influence results 
in a field environment. For example, Herr et al. (1983) examined the virulence of $15 \mathrm{D}$. helianthi isolates from Ohio on three sunflower commercial hybrids (Dahlgren DO844, RBA 800G, and Stauffer 3101 ) in the greenhouse and observed variation in size of the cankers, number of affected leaves, and the rate of disease development. Viguié et al. (1999) inoculated seven D. helianthi isolates from France on leaves, stems, and capitula of six sunflower hybrids and observed significant isolate by genotype interaction, indicating that the isolates varied in their aggressiveness on sunflower hybrids. Hence, Viguié et al. (1999) suggested that it is important to select an aggressive isolate or few isolates with known variability in aggressiveness for use in tests on sunflower genotypes for Diaporthe/Phomopsis resistance.

Artificial inoculation techniques in a controlled environment typically are less costly, labor and time sensitive, and more easily repeated. These greenhouse-based inoculation techniques can be used to evaluate pathogens for their aggressiveness and germplasm for resistance. Mathew et al. (2018) examined four different inoculation methods including a straw method (Encheva and Kiryakov 2002) stem and petiole wound inoculation methods (Thompson et al. 2011), and mycelium contact method (Thompson et al. 2011), and they determined the stem-wound method to be the most effective and user friendly way to evaluate Phomopsis stem canker of sunflower under controlled conditions.

The specific objectives of this study were 1) to compare the aggressiveness of isolates of $D$. helianthi and $D$. gulyae under greenhouse conditions to select a single aggressive isolate representative of the two pathogens and 2) to evaluate 49 sunflower accessions from the cultivated sunflower germplasm (Marek 2016) for resistance to $D$. helianthi and D. gulyae.

\section{Collection of D. helianthi and D. gulyae Isolates}

Five $D$. helianthi and five $D$. gulyae isolates were randomly selected from collections made during a survey coordinated by the National Sunflower Association in South Dakota in 2015 and 2016 (Table 1). Briefly, a total of 20 plant samples exhibiting symptoms of Phomopsis stem canker (brown to black stem lesion typically $>15 \mathrm{~cm}$ in length) were collected along two random transects (10 m long) in eight commercial sunflower fields. All fields were located in South Dakota and selected arbitrarily with a minimum distance separating each field of at least $5 \mathrm{~km}$. Inoculated plant samples were washed with tap water for $5 \mathrm{~min}$, and four pieces ( $10 \mathrm{~mm}$ long) were cut from infected stem tissue. The stem pieces were surface sterilized in sodium hypochlorite $(0.05 \%)$ and ethanol $(70 \%)$ for $1 \mathrm{~min}$ each, rinsed twice in sterile distilled water, and blotted dry on sterile filter papers. The four stem pieces were placed on potato dextrose agar (PDA), which was prepared following the protocol of Leslie and Summerell (2006). The PDA plates were incubated at $22^{\circ} \mathrm{C}$ for 10 days under $12 \mathrm{~h}$ of alternating light and dark conditions. Cultures were scored for presence or absence of Diaporthe based on morphological characteristics on PDA such as mycelial growth, and pycnidia and conidia formation (Barnett and Hunter 1972; Mathew et al. 2015). After 10 days, Diaporthe isolates were hyphal tipped and transferred to fresh plates of PDA amended with $0.02 \%$ streptomycin sulfate to prevent bacterial contamination. The isolates were identified as $D$. helianthi or D. gulyae by amplifying and sequencing the translation elongation factor 1-alpha $(\mathrm{EF} 1-\alpha)$ gene region using EF1-728F and EF1-986R primers (Carbone and Kohn 1999) as well as the internal transcribed spacer (ITS) gene region using ITS1 and ITS4 primers (White et al. 1990). For the aggressiveness study, isolates of D. helianthi and D. gulyae were freshly cultured on PDA and incubated at $22^{\circ} \mathrm{C}$ for 10 days under $12 \mathrm{~h}$ of alternating light and dark conditions. Mycelial plugs ( $4 \mathrm{~mm}$ in diameter) taken from the margin of the growing colony of each of the total 10 Diaporthe isolates were used as inoculum for the aggressiveness experiment.

\section{Aggressiveness Comparison of $D$. helianthi and D. gulyae Isolates}

To compare the aggressiveness between species and among isolates, the stem-wound method was used (Mathew et al. 2015, 2018). The experiment was performed as a completely randomized design with five isolates of $D$. helianthi and five isolates of D. gulyae as treatments, and the experiment was conducted twice. Each treatment was replicated six times (six plants per experiment).

TABLE 1

Median, mean rank, and relative treatment effects (REs) for Phomopsis stem canker severity caused by Diaporthe helianthi and D. gulyae isolates on susceptible confection inbred 'HA 288' in the greenhouse at 14 days after inoculation

\begin{tabular}{|c|c|c|c|c|c|}
\hline Isolate & Species & Location; year & Median $^{a}$ & Mean rank & Estimated RE $\mathbf{b}^{\mathbf{b}}$ \\
\hline DIA-08 & D. helianthi & Hand, SD; 2015 & 4.0 & 42.7 & $0.54(0.47,0.61)$ \\
\hline DIA-03 & D. helianthi & Hughes, SD, 2015 & 4.0 & 49.9 & $0.60(0.37,0.79)$ \\
\hline DIA-07 & D. helianthi & Brookings, SD; 2015 & 4.0 & 50.3 & $0.54(0.47,0.61)$ \\
\hline DIA-06 & D. helianthi & Sully, SD; 2015 & 4.5 & 45.7 & $0.72(0.41,0.89)$ \\
\hline DIA-24 & D. helianthi & Stanley, SD; 2016 & 4.0 & 50.3 & $0.60(0.48,0.70)$ \\
\hline DIA-01 & D. gulyae & Sully, SD; 2015 & 4.0 & 34.8 & $0.53(0.35,0.71)$ \\
\hline DIA-15 & D. gulyae & Faulk, SD; 2016 & 3.5 & 30.9 & $0.33(0.19,0.52)$ \\
\hline DIA-12 & D. gulyae & Sully, SD; 2016 & 4.0 & 46.0 & $0.46(0.26,0.68)$ \\
\hline
\end{tabular}

${ }^{\text {a }}$ Disease severity rating evaluated at 14 days after inoculation on sunflower plants using a 0 to 5 rating scale from Mathew et al. (2015) and Thompson et al. (2011), where $0=$ no discoloration; $1=$ low level discoloration at site of inoculation; $2=$ slight discoloration or lesion 1 to $2 \mathrm{~mm}$ in length; $3=$ necrotic lesions 2 to $5 \mathrm{~mm}$ in length, some colored stem streaking, leaf wilting, and twisting; $4=$ lesions 5 to $10 \mathrm{~mm}$ in length, significant necrosis and dark colored stem streaking, leaf and plant wilting, twisting, stunting, and some lodging; and $5=$ lesions exceeding $10 \mathrm{~mm}$ in length, severe leaf necrosis, lodging, or plant death.

${ }^{\mathrm{b}}$ For statistical analyses, data from the two experimental repeats were analyzed for homogeneity of variance using Bartlett's test in SAS (version 9.3, SAS Institute, Cary, NC). Based on the results of Bartlett's homogeneity test, variances of the two experimental repeats were homogenous and data were combined for nonparametric analyses. RE and confidence interval (95\%, in parentheses) were calculated using the nonparametric methods for ordinal data described by Shah and Madden (2004). No significant differences in RE was observed among Diaporthe isolates $(P>0.05)$. 
The stems of susceptible confection inbred 'HA 288' (Mathew et al. 2015) were wounded with a sterile scalpel at the V6 to V8 growth stage (six to eight true leaves, Berglund 2007) on the second internode (approximately $3 \mathrm{~cm}$ from the soil line), and a Diaportheinfested mycelial plug was placed on the wound and secured with Parafilm (Mathew et al. 2015). All accessions were grown at $25 \pm$ $2{ }^{\circ} \mathrm{C}$ under 16 -h light/dark conditions in the greenhouse and watered every 3 days. Plants were evaluated for lesion development at 14 days after inoculation on a scale of 0 to 5 , where $0=$ no discoloration; 1 = low level discoloration at site of inoculation; $2=$ slight discoloration or lesion 1 to $2 \mathrm{~mm}$ in length; $3=$ necrotic lesions 2 to $5 \mathrm{~mm}$ in length, some colored stem streaking, leaf wilting, and twisting; $4=$ lesions 5 to $10 \mathrm{~mm}$ in length, significant necrosis and dark colored stem streaking, leaf and plant wilting, twisting, stunting, and some lodging; and $5=$ lesions exceeding $10 \mathrm{~mm}$ in length, severe leaf necrosis, lodging, or plant death (Mathew et al. 2015; Thompson et al. 2011). In addition, proof of pathogenicity (Koch's postulates) was completed by plating inoculated sunflower plants on PDA and confirming the recovered pathogen via sequencing of the EF1- $\alpha$ and ITS gene regions (Carbone and Kohn 1999; White et al. 1990).

For statistical analyses, data from the experimental repeats were analyzed for homogeneity of variance using Bartlett's test in SAS (version 9.3, SAS Institute, Cary, NC). Based on the results of Bartlett's homogeneity test, variances of the two experimental repeats were homogenous, and data were combined for analyses using the nonparametric methods of Brunner et al. (2002) as described by Shah and Madden (2004). The nonparametric analysis was adopted since the disease severity was assessed using an ordinal rating scale of 0 to 5 (Mathew et al. 2015; Thompson et al. 2011). For the aggressiveness study, the median disease severity and the respective ranks were calculated for each Diaporthe isolate using the PROC RANK procedure in SAS. As defined in Shah and Madden (2004) and discussed in Akritas (1991), "if $R_{i k}$ is the rank of $X_{i k}$ among all $N$ observations, the mean rank for the $i$ th treatment can be written as

$$
\bar{R}_{i}=\frac{1}{n_{i}} \sum_{k=1}^{n_{i}} R_{i k} "
$$

The PROC RANK procedure was followed by PROC MIXED in SAS to generate relative treatment effects (RE) from the ranks for each Diaporthe isolate. The RE $\left(\hat{p}_{i}\right)$, defined as probabilities means derived from the marginal distribution functions of the dependent variable, was estimated from the ranks as

$$
\hat{p}_{i}=\frac{1}{N}\left(\bar{R}_{i \cdot}-\frac{1}{2}\right)
$$

where $\bar{R}_{i}$. is the mean rank of the treatments and $N$ is the total number of observations (Singer et al. 2004). The REs corresponding to each treatment (Diaporthe isolates) were compared by calculating 95\% confidence intervals using the LD_CI macro (Brunner et al. 2002) in SAS at $P \leq 0.05$ (Table 1). The control plants (inoculated with a noninfested PDA plug) did not show any symptoms, nor were the pathogens recovered. Hence, the disease rating of the control plants $(0=$ no discoloration) was not included in the statistical analyses.

All Diaporthe isolates were pathogenic on sunflower, but there were no significant differences $(P>0.05)$ in disease severity (expressed in terms of relative effects) among isolates. Our results are consistent with the findings of Mathew et al. (2015), in which 10
D. helianthi isolates and $10 \mathrm{D}$. gulyae isolates (different from those used in this current study) were selected from Minnesota, North Dakota, and South Dakota to study the aggressiveness of the two pathogens. For the next experiment, to screen accessions for resistance to the two species, $D$. helianthi isolate DIA-06 and $D$. gulyae isolate DIA-01 were selected. These isolates were selected as representative, had high median disease ratings (4.5 and 4.0, respectively), and had the highest REs among the Diaporthe isolates (Table 1).

\section{Acquisition of Cultivated Sunflower Accessions}

Forty-nine cultivated sunflower accessions and one additional susceptible check, HA 288 (PI 552934), were selected to be screened for resistance to D. helianthi and D. gulyae. Selection of accessions was based on a preliminary field study, in which 271 USDA accessions consisting of inbred lines, open pollinated populations, and breeding populations (Marek 2016) were screened for Phomopsis stem canker resistance under natural inoculum in a nonreplicated field trial in Brookings, SD (Feng et al. 2015). Among the 271 accessions, only 49 exhibited a resistant (or possibly escape) reaction to Phomopsis stem canker (no Phomopsis stem canker lesion was observed on the leaf or stem). Seeds of the 49 accessions and the susceptible confection inbred HA 288 (PI 552934) for this study were provided by Laura Marek (Iowa State University, Ames, IA). The 490 total accessions originated from the United States (40), Argentina (2), Hungary (2), Czechoslovakia (1), Austria (1), Canada (1), Poland (1), China (1), and Kazakhstan (1) (Table 2).

\section{Identification of Accessions Resistant to D. helianthi and D. gulyae}

The screening study was performed separately for $D$. helianthi and D. gulyae for a total of three times per pathogen. The experiment was designed as a completely randomized design, and each of the sunflower accessions was replicated six times (six plants) per experimental repeat. The sunflower inbred HA 288 was used as the susceptible check in the study. Two seeds of each accession were planted into 7.5-liter plastic pots (three pots per accession per experimental repeat) filled with moist potting soil (Sunshine Mix number 1, Sun Grow Horticulture Products, Belleview, WA). All accessions were grown under $16 \mathrm{~h}$ of alternating light and dark conditions at $25 \pm 2{ }^{\circ} \mathrm{C}$ and watered every 3 days in the greenhouse. The stem-wound method, as previously described, was used for the experiment. As such, mycelial plugs ( $4 \mathrm{~mm}$ in diameter) taken from the margin of the growing colony of D. helianthi (DIA-06) and D. gulyae (DIA-01) were used as the inoculum for the screening experiment. Plants were assessed for Phomopsis stem canker development at 14 days after inoculation on a scale of 0 to 5 (Mathew et al. 2015; Thompson et al. 2011).

For each pathogen, the homogeneity of variance between the three experimental repeats was satisfied before combining the results from the experiments. Test statistics were calculated separately for the $D$. helianthi and $D$. gulyae experiments using nonparametric methods in SAS (Shah and Madden 2004) as described previously. To determine the response of sunflower accessions to $D$. helianthi or D. gulyae, the ranked disease severity was used to estimate the REs and their $95 \%$ confidence intervals in SAS.

A significant effect of the sunflower accession $(P<0.0001)$ was observed for disease severity (expressed in terms of RE) caused by $D$. helianthi and D. gulyae, indicating that there were differences in the susceptibility of accessions to $D$. helianthi and $D$. gulyae at 14 days after inoculation (Table 2). For D. helianthi, 13 of the 49 accessions (PI 507894, PI 507911, PI 509064, PI 531366, PI 
TABLE 2

Median, mean rank, and relative treatment effects (REs) for Phomopsis stem canker severity caused by Diaporthe helianthi and $D$. gulyae on sunflower accessions in the greenhouse at 14 days after inoculation

\begin{tabular}{|c|c|c|c|c|c|c|c|}
\hline \multirow[b]{2}{*}{ Accession } & \multirow[b]{2}{*}{ Country of origin } & \multicolumn{3}{|c|}{ D. helianthi } & \multicolumn{3}{|c|}{ D. gulyae } \\
\hline & & Median $^{a}$ & Mean rank & Estimated $\mathbf{R E}^{\mathbf{b}}$ & Median $^{a}$ & Mean rank & Estimated $\mathbf{R E}^{\mathbf{b}}$ \\
\hline 162784 & Argentina & 4.0 & 250.0 & $0.58(0.38,0.75)$ & 4.0 & 235.9 & $0.54(0.40,0.68)$ \\
\hline 219649 & Austria & 4.0 & 271.6 & $0.63(0.46,0.77)$ & 4.0 & 294.3 & $0.68(0.50,0.82)$ \\
\hline 369359 & U.S.A. & 4.0 & 212.9 & $0.49(0.37,0.62)$ & 3.5 & 186.8 & $0.43(0.28,0.60)$ \\
\hline 386230 & Kazakhstan & 4.0 & 250.0 & $0.58(0.38,0.75)$ & 3.5 & 220.6 & $0.51(0.29,0.73)$ \\
\hline 507894 & Hungary & 3.5 & 162.0 & $0.37 *(0.23,0.54)$ & 4.0 & 211.3 & $0.49(0.33,0.65)$ \\
\hline 507911 & Hungary & 3.0 & 148.2 & $0.34 *(0.22,0.49)$ & 3.0 & 162.2 & $0.37(0.23,0.54)$ \\
\hline 509064 & U.S.A. & 3.0 & 148.2 & $0.34 *(0.22,0.49)$ & 3.0 & 162.2 & $0.37(0.23,0.54)$ \\
\hline 531366 & Poland & 3.5 & 154.3 & $0.36^{*}(0.20,0.54)$ & 4.0 & 260.4 & $0.60(0.48,0.71)$ \\
\hline 531389 & Czechoslovakia & 3.0 & 140.4 & $0.32 *(0.19,0.49)$ & 4.0 & 211.3 & $0.49(0.33,0.65)$ \\
\hline 534653 & U.S.A. & 4.0 & 234.4 & $0.54(0.44,0.64)$ & 4.0 & 285.0 & $0.66(0.63,0.68)$ \\
\hline 543745 & U.S.A. & 4.0 & 231.4 & $0.53(0.37,0.69)$ & 3.5 & 177.1 & $0.41(0.24,0.60)$ \\
\hline 549002 & U.S.A. & 3.0 & 118.9 & $0.27 *(0.16,0.43)$ & 4.0 & 260.4 & $0.60(0.48,0.71)$ \\
\hline 549014 & U.S.A. & 4.0 & 311.7 & $0.72(0.58,0.82)$ & 4.0 & 318.9 & $0.74(0.63,0.82)$ \\
\hline $552934^{\mathrm{c}}$ & U.S.A. & 4.0 & 274.6 & $0.63(0.55,0.72)$ & 4.0 & 269.8 & $0.62(0.41,0.79)$ \\
\hline 552939 & U.S.A. & 3.5 & 148.2 & $0.34 *(0.22,0.49)$ & 3.5 & 88.5 & $0.20 *(0.18,0.23)$ \\
\hline 552940 & U.S.A. & 4.0 & 228.5 & $0.53(0.25,0.79)$ & 3.5 & 186.8 & $0.43(0.28,0.60)$ \\
\hline 552944 & U.S.A. & 4.0 & 228.5 & $0.53(0.25,0.79)$ & 4.0 & 225.3 & $0.52(0.35,0.69)$ \\
\hline 560145 & U.S.A. & 3.5 & 169.8 & $0.39 *(0.26,0.54)$ & 3.0 & 162.2 & $0.37(0.23,0.54)$ \\
\hline 561918 & U.S.A. & 4.0 & 256.0 & $0.59(0.56,0.62)$ & 1.0 & 6.8 & $0.01 *(0.01,0.02)$ \\
\hline 578872 & U.S.A. & 4.0 & 253.0 & $0.58(0.44,0.71)$ & 4.0 & 235.9 & $0.54(0.40,0.68)$ \\
\hline 597366 & U.S.A. & 4.0 & 274.6 & $0.63(0.55,0.72)$ & 4.0 & 335.8 & $0.78(0.65,0.87)$ \\
\hline 597367 & U.S.A. & 4.0 & 250.0 & $0.58(0.38,0.75)$ & 4.0 & 211.3 & $0.49(0.33,0.65)$ \\
\hline 597368 & U.S.A. & 4.0 & 234.4 & $0.54(0.44,0.64)$ & 4.0 & 235.9 & $0.54(0.40,0.68)$ \\
\hline 597377 & U.S.A. & 4.0 & 242.3 & $0.56(0.35,0.75)$ & 3.0 & 211.3 & $0.49(0.33,0.65)$ \\
\hline 599753 & U.S.A. & 4.0 & 160.1 & $0.37(0.22,0.55)$ & 4.0 & 186.7 & $0.43(0.28,0.60)$ \\
\hline 599762 & U.S.A. & 4.0 & 223.7 & $0.52(0.34,0.69)$ & 4.0 & 235.9 & $0.54(0.40,0.68)$ \\
\hline 599765 & U.S.A. & 3.5 & 169.8 & $0.39 *(0.26,0.54)$ & 4.0 & 301.9 & $0.70(0.61,0.77)$ \\
\hline 599781 & U.S.A. & 4.0 & 212.9 & $0.49(0.37,0.62)$ & 3.0 & 137.6 & $0.32(0.19,0.48)$ \\
\hline 617099 & U.S.A. & 3.5 & 180.6 & $0.42(0.23,0.63)$ & 4.5 & 352.8 & $0.82(0.67,0.90)$ \\
\hline 618725 & U.S.A. & 4.0 & 311.7 & $0.72(0.58,0.82)$ & 3.0 & 113.1 & $0.26 *(0.17,0.39)$ \\
\hline 632342 & U.S.A. & 4.0 & 271.6 & $0.63(0.46,0.77)$ & 3.0 & 113.1 & $0.26 *(0.17,0.39)$ \\
\hline 632339 & U.S.A. & 4.0 & 234.4 & $0.54(0.44,0.64)$ & 4.0 & 260.4 & $0.60(0.49,0.71)$ \\
\hline 633748 & U.S.A. & 3.0 & 140.4 & $0.32 *(0.19,0.49)$ & 4.0 & 260.4 & $0.60(0.49,0.71)$ \\
\hline 642777 & U.S.A. & 4.0 & 242.3 & $0.56(0.35,0.75)$ & 3.0 & 142.0 & $0.33(0.17,0.54)$ \\
\hline 650348 & China & 4.0 & 212.9 & $0.49(0.37,0.62)$ & 3.0 & 162.2 & $0.37(0.23,0.54)$ \\
\hline 650359 & NA & 3.0 & 148.2 & $0.34 *(0.22,0.49)$ & 4.0 & 285.0 & $0.66(0.63,0.68)$ \\
\hline 650523 & Canada & 4.0 & 293.1 & $0.68(0.56,0.78)$ & 4.5 & 303.6 & $0.70(0.44,0.87)$ \\
\hline 650571 & U.S.A. & 4.0 & 209.9 & $0.48(0.31,0.66)$ & 4.0 & 211.3 & $0.49(0.33,0.65)$ \\
\hline 650754 & U.S.A. & 4.0 & 258.9 & $0.60(0.36,0.80)$ & 4.0 & 235.9 & $0.54(0.40,0.68)$ \\
\hline 650794 & Argentina & 3.5 & 160.1 & $0.37(0.22,0.55)$ & 4.0 & 211.3 & $0.49(0.33,0.65)$ \\
\hline 655014 & U.S.A. & 4.0 & 175.8 & $0.41(0.25,0.59)$ & 3.5 & 186.8 & $0.43(0.28,0.60)$ \\
\hline 664179 & U.S.A. & 3.0 & 140.4 & $0.32 *(0.19,0.49)$ & 4.0 & 252.8 & $0.58(0.40,0.74)$ \\
\hline 664189 & U.S.A. & 4.0 & 181.6 & $0.42(0.27,0.59)$ & 4.0 & 228.3 & $0.53(0.34,0.71)$ \\
\hline 664193 & U.S.A. & 4.0 & 247.0 & $0.57(0.34,0.78)$ & 4.0 & 235.9 & $0.54(0.40,0.68)$ \\
\hline 664204 & U.S.A. & 4.5 & 330.3 & $0.76(0.62,0.86)$ & 3.0 & 162.2 & $0.37(0.23,0.54)$ \\
\hline 664225 & U.S.A. & 4.0 & 274.6 & $0.63(0.55,0.72)$ & 4.0 & 235.9 & $0.54(0.40,0.68)$ \\
\hline 664227 & U.S.A. & 4.0 & 293.1 & $0.68(0.56,0.78)$ & 3.5 & 186.8 & $0.43(0.28,0.60)$ \\
\hline 664230 & U.S.A. & 4.0 & 293.1 & $0.68(0.56,0.78)$ & 3.0 & 142.9 & $0.33(0.17,0.54)$ \\
\hline 664232 & U.S.A. & 1.0 & 7.9 & $0.02 *(0.01,0.03)$ & 3.5 & 177.1 & $0.41(0.24,0.60)$ \\
\hline 664233 & U.S.A. & 4.0 & 250.0 & $0.58(0.38,0.75)$ & 4.0 & 235.9 & $0.54(0.40,0.68)$ \\
\hline
\end{tabular}

${ }^{\text {a }}$ Disease severity rating evaluated at 14 days after inoculation on sunflower plants using a 0 to 5 rating scale from Mathew et al. (2015) and Thompson et al. (2011), where $0=$ no discoloration; $1=$ low level discoloration at site of inoculation; $2=$ slight discoloration or lesion 1 to $2 \mathrm{~mm}$ in length; $3=$ necrotic lesions 2 to $5 \mathrm{~mm}$ in length, some colored stem streaking, leaf wilting, and twisting; 4 = lesions 5 to $10 \mathrm{~mm}$ in length, significant necrosis and dark colored stem streaking, leaf and plant wilting, twisting, stunting, and some lodging; and $5=$ lesions exceeding $10 \mathrm{~mm}$ in length, severe leaf necrosis, lodging, or plant death.

${ }^{b}$ For statistical analyses, data from the three experimental repeats for each pathogen were analyzed for homogeneity of variance using Bartlett's test in SAS (version 9.3, SAS Institute, Cary, NC). Based on the results of Bartlett's homogeneity test, variances of the three experimental repeats were homogenous and data were combined for nonparametric analyses. RE and confidence interval (95\%, in parentheses) were calculated using the nonparametric methods for ordinal data described by Shah and Madden (2004). Asterisk $\left(^{*}\right)$ indicates that the RE is significantly different among treatments $(P \leq 0.05)$.

c 552934 is HA 288, the susceptible check. 
531389, PI 549002, PI 552939, PI 560145, PI 599765, PI 633748, PI 650359, PI 664179, and PI 664232) were significantly less susceptible compared with HA 288 (PI 552934), based on $95 \%$ confidence intervals of their REs (Table 2). Among the 13 sunflower accessions, PI 664232 had the lowest RE upon inoculation with $D$. helianthi. For D. gulyae, 4 of 49 accessions (PI 552939, PI 561918, PI 618725, and PI 632342) were significantly less susceptible compared with HA 288 based on 95\% confidence intervals of their REs (Table 2). Among those four sunflower accessions, PI 561918 had the lowest RE upon inoculation with D. gulyae. Notably, PI 552939 was the only accession more resistant to both $D$. helianthi and D. gulyae compared with HA 288. No Phomopsis stem canker symptoms were observed on the control plants, nor were the pathogens isolated from any of them.

\section{Implications for Managing Phomopsis Stem Canker with Genetic Resistance}

Despite 13 and 4 accessions identified as resistant to $D$. helianthi and D. gulyae, respectively, only one accession (PI 552939) was determined to be more resistant than the susceptible check to both of the pathogens. This suggests that management of Phomopsis stem canker with only genetic resistance could be difficult in the field. Given that both D. helianthi and D. gulyae are common (precise pathogen distribution is unclear) in the primary U.S. sunflower growing area, it appears that hybrids resistant to only one of the pathogens may be insufficient for management. Recent observations made in sunflower crop performance trials in South Dakota have suggested that hybrids "resistant" to Phomopsis stem canker one year may be "susceptible" to the disease the next year (F. Mathew, unpublished). It is possible these inconsistent reactions may be owing to the differences in causal species or pathogen strains among sunflower production fields. Because both $D$. gulyae and $D$. helianthi are thought to be common in the growing region, identification of the specific causal agent(s) of Phomopsis stem canker in screening nurseries and crop performance trials is important for breeding and management recommendations.

In this study, the 49 accessions did not all show resistance in the greenhouse, despite these accessions being selected because they were less susceptible in a field experiment (Feng et al. 2015). Importantly, those 49 accessions were selected in a nonreplicated naturally infected field trial, so these results should be viewed with caution, and disease escape is possible. However, it is possible that additional factors could contribute to inconsistency of results between greenhouse and field studies. Importantly, the natural infection process is thought to begin as ascospores infect the leaf, and the pathogen grows through the petiole and eventually into the stem. Greenhouse-based studies often use different inoculum sources and infection origins. Previous studies screening germplasm for resistance have demonstrated mixed results when data are compared between artificial inoculation methods in greenhouse experiments and field evaluations. Encheva and Kiryakov (2002) found a high and significant level of correlation between results of straw test screening and natural field screening, whereas Viguié et al. (1999) found both significant and nonsignificant correlations between artificial inoculation methods in the greenhouse and field experiments. Several explanations could explain this, most notably the possibility that stem and leaf resistance could be inherited independently (Degener et al. 1999) and that isolates of differing virulence and/or species were naturally occurring in field experiments but were absent in controlled inoculated experiments, which would could alter the species-host reaction (Bertrand and Tourvieille 1987; Viguié et al. 1999).

\section{Conclusions and Recommendations}

Given the results of this study, it is essential to evaluate germplasm regarding both species when breeding for resistance to Phomopsis stem canker in the United States. This study suggests that germplasm evaluations in controlled environments, in which it can be ensured that both pathogens are present, should be incorporated in the breeding process. Even then, breeders should be advised that this resistance may be unlikely to hold up internationally, given that several additional pathogenic species exist globally. Currently, it is important that growers be advised that a "resistant" hybrid may be challenged in the field, even if that same hybrid appeared resistant in a previous year. As such, planting a resistant hybrid should not be the sole management tool used to manage the disease, particularly in areas where Phomopsis stem canker is common, such as Minnesota, North Dakota, and South Dakota. Effective management of Phomopsis stem canker will likely depend on continued development of genetic resistance, in concert with improvement of other integrated pest management tools, such as better recommendations for fungicide use (efficacy, timing, and modeling), better understanding of pathogen host range, and crop rotation recommendations.

\section{Acknowledgments}

We thank Jiuhuan Feng, Ruth Beck, Kathy Grady, Anjana Adhikari, Brian Kontz, Krishna Ghimire, Nathan Braun, Ahmed Gebreil, Rawnaq Chowdhury, Ana Micijevic, Paul Okello, John Posch, Antoine Baggett, Phillip Rozeboom, Bisheesh Manandhar, and Jharna Pokhrel for their support in this research.

\section{Literature Cited}

Akritas, M. G. 1991. Limitations of the rank transform procedure: A study of repeated measures designs, Part I. J. Am. Stat. Assoc. 86:457-460.

Barnett, H. L., and Hunter, B. B. 1972. Illustrated Genera of Imperfect Fungi, 3rd Ed. Burgess Publishing, Minneapolis, MN.

Berglund, D. R. 2007. Sunflower Production. Publication A-1331. North Dakota State University Cooperative Extension Service, Fargo.

Bertrand, F., and Tourvieille, D. 1987. Phomopsis du tournesol: Test de sélection. Inf. tech. CETIOM 98:12-18.

Brunner, E., Domhof, S., and Langer, F. 2002. Nonparametric Analysis of Longitudinal Data in Factorial Experiments. Wiley, New York.

Carbone, I., and Kohn, L. M. 1999. A method for designing primer sets for speciation studies in filamentous ascomycetes. Mycologia 91:553-556.

Cuk, L. 1982. Using wild species in sunflower breeding. Uljarstvo 1:23-27.

Degener, J., Melchinger, E. A., and Hahn, V. 1999. Inheritance of resistance to Phomopsis in sunflower: Study of leaf and stem resistance after artificial and natural infection. Helia 22:105-115.

Dozet, B. M. 1990. Resistance to Diaporthe/Phomopsis helianthi Munt.-Cvet. et al. wild sunflower species. Pages 86-88 in: Proceedings of the 12th Sunflower Research Workshop, Fargo, ND, 9-10 January 1990. National Sunflower Association, Bismarck, ND.

Encheva, V., and Kiryakov, I. 2002. A method for evaluation of sunflower resistance to Diaporthe/Phomopsis helianthi Munt. Cvet. et al. Bulg. J. Agric. Sci. 8: 219-222.

Feng, J., Grady, K., Gu, X., and Mathew, F. 2015. Characterization of a sunflower (Helianthus annuus L.) germplasm collection for resistance to Phomopsis stem canker and adaptation in South Dakota. Phytopathology 105:S4.42.

Gulya, T. J., and Kandel, H. 2016. NSA Yield and Pest Survey-2015. In: Proceedings of the 38th Sunflower Research Forum, Fargo, ND, January 12-13, 2016. National Sunflower Association, Mandan, ND.

Gulya, T. J., Marek, L. F., and Gavrilova, V. 2009. Disease resistance in cultivated sunflower derived from public germplasm collections. Pages 7-18 in: Proceedings of the International Symposium Sunflower Breeding for Resistance to Diseases, Krasnodar, Russia.

Harveson, R. M., Markell, S. G., Block, C. C., and Gulya, T. J. 2016. Compendium of Sunflower Diseases, 1st Ed. American Phytopathological Society, St. Paul, MN.

Herr, L. J., Lipps, P. E., and Walters, B. H. 1983. Diaporthe stem canker of sunflower. Plant Dis. 67:911-913.

Langar, K., Griveau, Y., Serieys, H., and Berville, A. 2000. Analyse genetique de la resistance au Phomopsis (Diaporthe helianthi Munt.-Cvet. et al.) chez le tournesol 
cultive (Helianthus annuus L.). In: Proceedings of the 15th International Sunflower Conference, Toulouse, France, Tome II, K-90-95.

Leslie, J. F., and Summerell, B. A. 2006. The Fusarium Laboratory Manual. Blackwell Publishing, Ames, IA.

Marek, L. F. 2016. Sunflower genetic resources. Pages 31-44 in: Proceedings of the 19th International Sunflower Conference, Edirne, Turkey, 29 May-3 June 2016. Y. Kaya and S. Hasancebi, eds. International Sunflower Association, Paris.

Masirevic, S., and Gulya, T. J. 1992. Sclerotinia and Phomopsis-Two devastating sunflower pathogens. Field Crops Res. 30:271-300.

Mathew, F. M. 2014. Molecular characterization and pathogenicity of sunflower stem pathogens. Doctoral dissertation. North Dakota State University, Fargo. Retrieved from ProQuest dissertations database. Accession no. 3629478.

Mathew, F. M., Alananbeh, K. M., Heitkamp, E., Balbyshev, N., Castlebury, L., Gulya, T., and Markell, S. 2012. Reevaluation of Phomopsis species affecting sunflowers in the United States. In: Proceedings of the 34th Sunflower Research Workshop, 2012. Fargo, ND.

Mathew, F. M., Alananbeh, K. M., Jordahl, J. G., Meyer, S. M., Castlebury, L. A., Gulya, T. J., and Markell, S. G. 2015. Phomopsis stem canker: A reemerging threat to sunflower (Helianthus annuus) in the United States. Phytopathology 105:990-997.

Mathew, F. M., Jordahl, J. G., Gulya, T. J., and Markell, S. G. 2018. Comparison of greenhouse-based inoculation methods to study aggressiveness of Diaporthe helianthi isolates causing Phomopsis stem canker of sunflower (Helianthus annuus). Online publication. Plant Health Prog. 19:92-96.

Muntañola-Cvetković, M., Mihaljčević, M., and Petrov, M. 1985. On the identity of the causative agent of a serious Phomopsis-Diaporthe disease in sunflower plants. Nova Hedwigia 34:417-435.

Olson, T. R., Kontz, B., Gulya, T. J., Markell, S. G., and Mathew, F. M. 2017. First report of Diaporthe stewartii causing Phomopsis stem canker of sunflower (Helianthus annuus) in Minnesota. Plant Dis. 101:382.
Shah, D. A., and Madden, L. V. 2004. Nonparametric analysis of ordinal data in designed factorial experiments. Phytopathology 94:33-43.

Singer, J. M., Poleto, F. Z., and Rosa, P. 2004. Parametric and nonparametric analyses of repeated ordinal categorical data. Biometrical J. 46:460-473.

Škorić, D. 1984. Genetic resources in the Helianthus genus. Pages 37-73 in: Proceedings of the International Symposium on Science and Biotechnology for an Integral Sunflower Utilization, Bari, Italy, 25 October 1984. D. Škorić, ed.

Talukder, Z. I., Hulke, B. S., Marek, L. F., and Gulya, T. J. 2014. Sources of resistance to sunflower diseases in a global collection of domesticated USDA plant introductions. Crop Sci. 54:694-705.

Thompson, S. M., Tan, Y. P., Shivas, R. G., Neate, S. M., Morin, L., Bissett, A., and Aitken, E. A. B. 2015. Green and brown bridges between weeds and crops reveal novel Diaporthe species in Australia. Persoonia 35:39-49.

Thompson, S. M., Tan, Y. P., Young, A. J., Neate, S. M., Aitken, E. A. B., and Shivas, R. G. 2011. Stem cankers on sunflower (Helianthus annuus) in Australia reveal a complex of pathogenic Diaporthe (Phomopsis) species. Persoonia 27:80-89.

Udayanga, D., Castlebury, L. A., Rossman, A. Y., Chukeatirote, E., and Hyde, K. D. 2015. The Diaporthe sojae species complex: Phyologenetic reassessment of pathogens associated with soybean cucurbits and other field crops. Fungal Biol. 119:383-407.

Viguié, A., Vear, F., and de Labrouhe, D. T. 1999. Interactions between French isolates of Phomopsis/Diaporthe helianthi Munt.-Cvet. et al. and sunflower (Helianthus annuus L.) genotypes. Eur. J. Plant Pathol. 105:693-702.

Vrandečić, K., Ćosić, J., Jurković, D., Duvnjak, T., and Riccioni, L. 2009. First report of Diaporthe phaseolorum on sunflower (Helianthus annuus) in Croatia. Plant Dis. 93:1074.

White, T. J., Bruns, T., Lee, S., and Taylor, J. 1990. Amplification and direct sequencing of fungal ribosomal RNA genes for phylogenetics. Pages 315-322 in: PCR Protocols: A Guide to Methods and Applications. M. A. Innis, D. H. Gelfand, J. J. Sninsky, and T. J. White, eds. Academic Press, San Diego, CA. 